\title{
A Review: Digital Rights Management Sustainable Development in e-Commerce
}

\author{
Ranjeet Kumar \\ Indian Institute of Information \\ Technology, Deoghat Jhalwa \\ Allahabad Email-
}

\author{
R.C.Tripathi \\ Indian Institute of Information \\ Technology, Deoghat Jhalwa \\ Allahabad Email-
}

\author{
M.D.Tiwari \\ Indian Institute of Information \\ Technology, Deoghat Jhalwa \\ Allahabad Email-
}

\begin{abstract}
Strong encryption is an urgent need for e-commerce development, since it allows the privacy and secure transactions of the financial and other data. International regulations must support the spreading of e-commerce and the associated encryption techniques in order to establish a secure e-commerce environment that customers can trust and develop faith in international deployment of ecommerce solutions without restrictions. In the present paper, a pricing and license model for the fare use of the digital contents is proposed suitable for today's digital environment. Protection by way of Digital Rights Management (DRM) systems is emerging as a natural solution because it remains in force wherever the content goes. In contrast, a file that sits on a server behind the server's access control mechanism loses its protection once it is moved from the server. The meaning of the term "DRM" has been used so far in its most narrow sense and no longer reflects many of the recent developments in the technology used to manage copyrighted works in the digital age. The efforts made for a secure DRM approach for the secure content transactions over digital environment using latest technologies has been reviewed in the present paper to advocate finally for the most acceptable DRM architecture supporting audio, video, text, XML and other popular applications file formats to serve the dynamic needs of the market optimally.
\end{abstract}

Keywords: DRM System and Architecture, Digital Signature, Encryption method, Security for content access, Digital Copyright

\section{INTRODUCTION}

Piracy of online copyrighted works poses real threat to the creators and distributors of content. At the same time, technological and regulatory proposals to protect copyright have raised difficult questions about potential impacts on competition, innovation, public values, and consumer uses of copyrighted contents. Digital Rights Management technology offers great promise in protecting content and supporting new business models. However it is also characterized with great peril in exacerbating these potential impacts [1].

Digital rights management (DRM) is a generic term for access control technologies that can be used by hardware manufacturers, publishers, copyright holders and individuals aiming to impose limitations on the usage of digital content and devices [2]. The term generally doesn't refer to other forms of copy protection which can be circumvented without modifying the file or device. It can also refer to restrictions associated with specific instances of digital works or devices. Digital rights management is being used by companies such as Sony, Apple Inc, Microsoft, AOL and the BBC [3].

DRM is a collection of technologies that enable technically enforced licensing of digital information. A well designed DRM system provides- Governance - implementation of control or governance by the use of programming language methods executed in a secure environment, Secure association of usage rules with information in complex Copyright domain - Rules can be attached to content, embedded within content or can be delivered independently of content, by way of Persistent Protection using Cryptographic technique etc. DRM enables content providers to create licenses as per the agreement of the customer rigidly enforcing the use of existing content as per agreed conventions e.g. European Privacy Protection etc. There are several technologies and solutions that have been created to deal with business models and objectives. The DRM market attempts at standardization by way of the rights specification language XrML (eXtensible rights Markup Language) [4] and the ICE (Interchange Content Exchange) protocol. Proprietary solutions are usually obscure, and they do not specify what technologies are used, or how the protection of content and the usage control are made [5]. Proprietary solutions include specific solutions to define formats and business models, and large scale solutions can be used with several formats and business models.

\section{RELATED WORK}

Digital Right Management system was early developed as Content Scrambling System (CSS) and employed by the DVD Forum on films DVDs since 1996. CSS is implemented in simple encryption algorithm and required device manufacturers need to sign license agreements that restrict the inclusion of features, such as digital outputs that could be used to extract high-quality digital copies of the film, in their players. Another Application of the DRM is used in the Operating System of Microsoft and other similar profile companies. Microsoft's Windows Vista contains a DRM system called the Protected Media Path, which contains the Protected Video Path (PVP). PVP tries to stop DRM-restricted content from playing 
while unsigned software is running in order to prevent the unsigned software from accessing the content. Additionally, PVP can encrypt information during transmission to the monitor or the graphics card, which makes it more difficult to make unauthorized recordings [6].

Advanced Access Content System (AACS) is a DRM system for HD DVD. Blu-Ray Discs developed by the AACS are used by the Licensing Administrator, known as LLC (AACS LA), a consortium that includes Disney, Intel, Microsoft, Matsushita (Panasonic), Warner Brothers, IBM, Toshiba and Sony.

Windows Media DRM is a Digital Rights Management service for the Windows Media platform. It is designed to provide secure delivery of audio and/or video content over an IP network to a PC or other playback device in such a way that the distributor can control how that content is used [7].

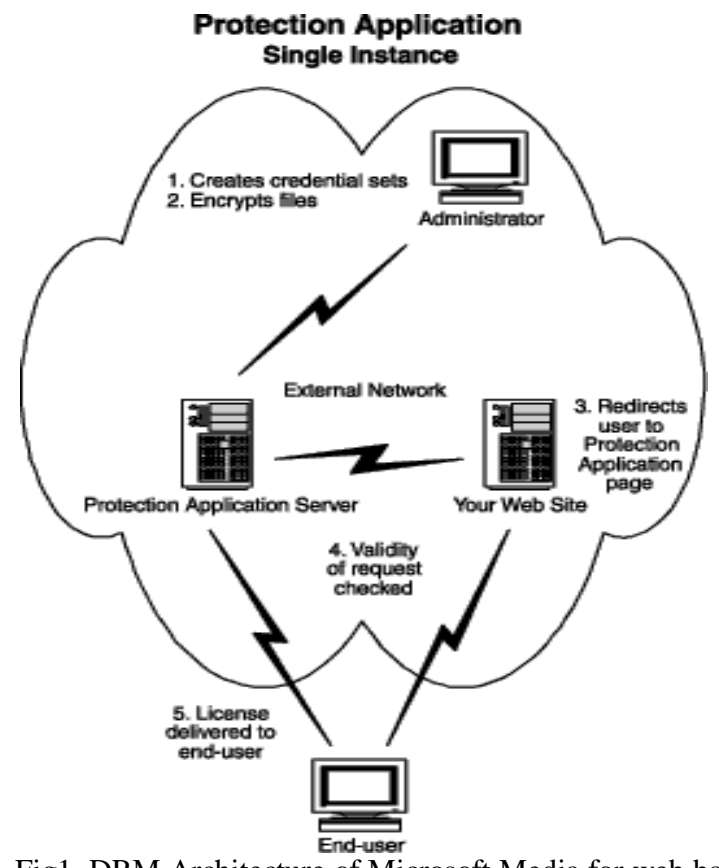

Fig1. DRM Architecture of Microsoft Media for web based

license distribution servers. [7][8]

In his proposed architecture of the DRM in the published paper "A Self Local License Digital Rights Management System by Mohsen Sharifi" [7], he defines the access of protected content by the user. The architecture controls all owner rights in the client side including all desired data usage limitations and distribution. It works like a transparent file system and all file system requests are redirected towards DRM system before other file system or operating system receives that file system. After receiving the file request it will recognize the file by an application. The target Application Recognizer is required to have a license for access of the data protected by the DRM and License manager is responsible for managing the protected data file system. Now License manager passes the requests and related licenses are granted by the
Encryption/Decryption Manager who sends request packages to file system layers of the relevant operating systems. It also does the encryption/decryption of the received request packages to be delivered to the target application.

\section{APPROACHES OF THE DRM ARCHITECTURE}

There are different approaches followed for Digital Rights Management for different purposes with appropriate security measures for different kinds of the contents. Digital Rights Management systems for some specific models are described below with an aim to illustrate the various points of their architecture.

\subsection{Proxy Architecture for DRM service}

Proxy architecture has been developed for the proxy applications as per the request of the user for accessing the content of the server. Request file creates the DRM request and sends it to the proxy file. After verifying over the request successfully, proxy file creates and sends the proxy DRM request to the server. The "Proxy DRM Request" can contain the whole "DRM Request" as an element or contain relative elements picked up from the "DRM Request". Similarly service request flow continues for other DRM request with the server [9]

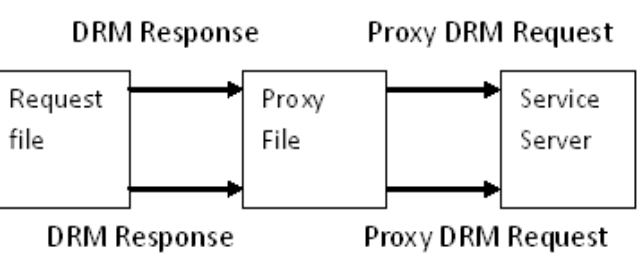

Figure2. Proxy Architecture for DRM Service [9]

The main idea behind the DRM application is to build up and to deliver effectively the trust mechanism since the Service Server should control the risk from all the devices that could access the service or content. It should be a trusted proxy mechanism for controlling all flows.

\subsection{Digital Content Distribution Management Architecture (DCDMA)}

There are three ways by which we can describe the DRM architecture. These are by way of the content server, the license server and the client [10]. The Digital Content Distribution Management Architecture (DCDMA) consists of the entities like the Client Entity, the Authentication Entity, the Content Entity, the License creation entity, the Distribution and Management Entity and the Authorization and Rights Distribution Entity. All above mentioned different modules work together for Digital Content Distribution Management Architecture (DCDMA) and provide a secure content access to the request client [5].

\subsection{SUN Architecture- DREAM}

The DreaM architecture for the management of the digital rights is an open source architecture which works in all 
equipments [11]. Fig 3 shows the working module of the architecture.

There are different modules for the different processes in the architecture. These include modules for Acquisition, Content Processing, Digital Asset Management, Distribution and Consumption. The packaging process involves combining content data/files with associated metadata and creating logical packages that include the defined business rules. The content used by the user must be specified by the license server which is generated by the user. Protected content and the associated keys/licenses must be distributed to the clients. The terms of usages are specified in the license in the machine readable language such as XML, or its any variant.

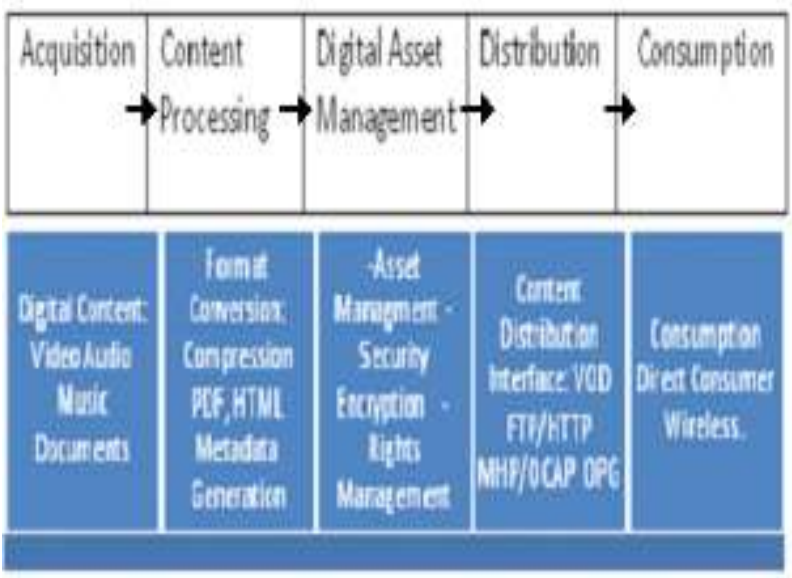

Fig.3 SUN Architecture DreaM.

\section{DRM ARCHITECTURE AND THEIR EFFICACY}

Some of the existing DRM architectures listed above and their efficacy is shown in the Table 1. Windows Media Rights Manager Architecture (WMRM) is a commercial architecture and developed by Microsoft. It provides a license for storage by due encrypting the digital data with a key separately. Other is Core Media Architecture which is Multi -DRM Architecture and supports the standards like OMA DRM and Windows Media DRM. SUN Architecture-DREAM is open source architecture and it helps on management of the digital rights which works in all equipments. In the packaging process, it combines the content data or files with associated metadata and crates logical packages that include the defined rules.

\begin{tabular}{|l|l|l|l|l|l|}
\hline & $\begin{array}{l}\text { WMR } \\
\text { M }\end{array}$ & $\begin{array}{l}\text { Core } \\
\text { Media }\end{array}$ & $\begin{array}{l}\text { Dream } \\
\text { SUN }\end{array}$ & $\begin{array}{l}\text { Liquid } \\
\text { Machine } \\
\mathrm{s}\end{array}$ & $\begin{array}{l}\text { Accepta } \\
\text { ble }\end{array}$ \\
\hline License & XRML & $\begin{array}{l}\text { XRML/ } \\
\text { ODRL }\end{array}$ & $\begin{array}{l}\text { Open } \\
\text { Source }\end{array}$ & $\begin{array}{l}\text { Own } \\
\text { policy } \\
\text { expressi }\end{array}$ & $\begin{array}{l}\text { MPEG- } \\
\text { REL } \\
\text { (ISO) }\end{array}$ \\
\hline
\end{tabular}

\begin{tabular}{|c|c|c|c|c|c|}
\hline & & & & on & \\
\hline $\begin{array}{l}\text { Digital } \\
\text { File } \\
\text { Format }\end{array}$ & Owner & $\begin{array}{l}\text { Windows } \\
\text { DRM } \\
\text { \&OMA } \\
\text { DRM }\end{array}$ & $\begin{array}{l}\text { Standard } \\
\text { Formats }\end{array}$ & Standard & $\begin{array}{l}\text { Standard } \\
\text { Formats }\end{array}$ \\
\hline $\begin{array}{l}\text { Digital } \\
\text { File } \\
\text { Types }\end{array}$ & $\begin{array}{l}\text { Audio, } \\
\text { Video }\end{array}$ & $\begin{array}{l}\text { Audio, } \\
\text { Video }\end{array}$ & $\begin{array}{l}\text { Audio, } \\
\text { Video, } \\
\text { Documen } \\
\text { ts }\end{array}$ & $\begin{array}{l}\text { Audio, } \\
\text { Video, } \\
\text { Docume } \\
\text { nts }\end{array}$ & $\begin{array}{l}\text { Audio, } \\
\text { Video, } \\
\text { Docume } \\
\text { nts, } \\
\text { Applicat } \\
\text { ion }\end{array}$ \\
\hline $\begin{array}{l}\text { Interoper } \\
\text { ability }\end{array}$ & Owner & $\begin{array}{l}\text { Interoper } \\
\text { able }\end{array}$ & $\begin{array}{l}\text { Interoper } \\
\text { able \& } \\
\text { Open } \\
\text { Source }\end{array}$ & $\begin{array}{l}\text { Interoper } \\
\text { able }\end{array}$ & $\begin{array}{l}\text { Interoper } \\
\text { able \& } \\
\text { Open } \\
\text { Source }\end{array}$ \\
\hline $\begin{array}{l}\text { Authenti } \\
\text { cation }\end{array}$ & $\begin{array}{l}\text { Equipm } \\
\text { ent and } \\
\text { Player }\end{array}$ & $\begin{array}{l}\text { Equipme } \\
\text { nt \& } \\
\text { Player }\end{array}$ & $\begin{array}{l}\text { User } \\
\text { Oriented }\end{array}$ & $\begin{array}{l}\text { User } \\
\text { Oriented }\end{array}$ & $\begin{array}{l}\text { Equipme } \\
\text { nt Player } \\
\text { User }\end{array}$ \\
\hline $\begin{array}{l}\text { Type of } \\
\text { licenses }\end{array}$ & Static & Static & $\begin{array}{l}\text { Can be } \\
\text { Dynamic }\end{array}$ & $\begin{array}{l}\text { Can be } \\
\text { Dynamic }\end{array}$ & Dynamic \\
\hline
\end{tabular}

Architecture

\section{ACCEPTABLE ARCHITECTURE}

DRM

Digital Rights Management standard Architecture consists of the Creation, Distribution, and Consumption of the digital contents. Above mentioned architectures are mostly based on owner file formats and these formats are generally for audio and video files. In the latest acceptable architecture of the DRM, the DRM Adaptable Architecture (DRMAA), it is proposed to support file formats like audio, video, text or other applications [12]. The licenses can be used according to context and in a dynamic manner. The client or user has the choice to associate the license with the equipment, the reading software or with its digital identifier according to his/her needs. 


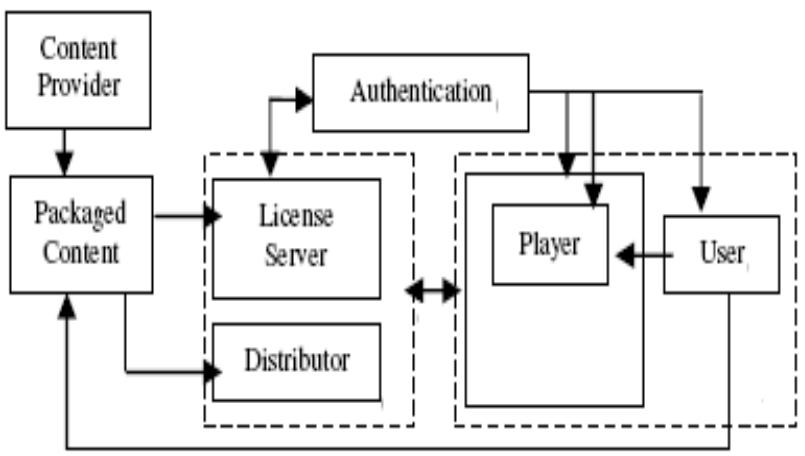

Fig 4. The Acceptable Architecture [12]

Fig4 shows the flexible and adaptable architecture which is alternative of the above mentioned architectures.

This architecture has many modules. The user module starts the procedure for consumption. Thereafter the producer authenticates the consumers. License server could be static or dynamic in nature and is associated with the user and/or the equipment and/or the player. The Content after being packaged is put on the distribution server. The contents may not be limited to audio and video files only. It could be XML, text or other applications also.

\section{CONCLUSION}

The various Digital Rights Management Architectures currently in the market have been reviewed in this paper. These are generally designed for the audio and video file formats which work mostly for static licenses. They are yet to cover the market dynamism. Limitations in this regard are sorted out in the acceptable DRM architecture which also support the XML, text and application file formats through the dynamic license authentication server for the needs of the dynamic market. It gives the user choice to associate the license with its digital identity, the equipment or the software of reading according to the needs of the consumer.

\section{REFERENCES}

[1] Bill Rosenblatt, DRM Watch Transitions to New Format, January 2009. http://www.drmwatch.com/article.php/3795151.
[2] Bill Rosenblatt and Gail Dykstra, Integrating Content Management with Digital Rights Management, GiantSteps Media Technology Strategies, May 14, 2003.

[3] Andres TORRUBI, Francisco J. MORA, Luis MARTI, Cryptography Regulations for E-commerce and Digital Rights Management Computers \& Security, Volume 20, Issue 8, Science Direct, 01 December 2001.

[4] Wang, X., Lao, G., DeMartini, T., Reddy, H., Nguyen, M. and Valenzuela, E. "XrML - eXtensible rights Markup Language", In: ACM Workshop on XML Security, USA, November, p. 71-79., 2002.

[5] Valerio Rosset, Cleber Vinicios Filippin, Carla Merkle Westphall, A DRM Architecture to Distribute and Protect Digital Contents Using Digital Licenses, Proceedings of the Advanced Industrial IEEE 2005 Conference on Telecommunications/Services Assurance with Partial and intermittent Resources.

[6] Digital Rights Management http://en.wikipedia.org/wiki/Digital_rights_management

[7] Mohsen Sharifi, A Self Local License Digital Rights Management System, Second IEEE International Conference on Digital Ecosystems and Technologies. 2008

[8] Digital Rights Management http://www.microsoft.com/windows/windowsmedia/forpros /drm/default.mspx

[9] Proxy Architecture for DRM Services, http://tools.ietf.org/html/draft-zhipeng-pkix-drm-proxyarchitecture-01\#section-3

[10] Rosenblatt, B., Trippe, B. and Mooney, S. "Digital rights Management - Business and Technology", M\&T Books, $1^{\text {st }}$ Edition, USA, 288 p, 2002

[11] David Sohn, Evaluating DRM: Building a Marketplace for the Convergent World, Centre for Democracy \& Technology, 7 September 2006, Version 1.0

[12] Morad Rafi, Mohsine El Euldj, Zouhair Guennoun, DRMAA: DRM Adaptable Architecture, EMI, Morocco, April, 2008. 